\title{
Value creation through omnichannel practices for multi-actor customers: an evolutionary view
}

Value creation through omnichannel practices

Ricardo Costa Climent

Department of Informatics and Media, Uppsala University, Uppsala, Sweden

Darek M. Haftor

Department of Informatics and Media, Uppsala University, Uppsala, Sweden and University of Economics and Human Sciences in Warsaw, Warszawa, Poland, and

Soumitra Chowdhury Department of Informatics, Linnaeus University, Vaxjö Sweden

\begin{abstract}
Purpose - The purpose of this paper is to investigate the omnichannel practices to porpose a conceptual overview to offer guidance on how to handle their inherent complexities.

Design/methodology/approach - This study is based on a literature review of more than 100 academics papers about the multichannel practices and omnichannel practices in the global market.

Findings - To this end, this paper identifies and addresses three limitations of the contemporary omnichannel literature: the failure to articulate the sources of value creation generated by omnichannel practices, the conception of omnichannel as targeting a single customer actor only and the static conception of omnichannel practices. In response to these limitations, this study offers the following: four sources of value creation based on the business model concept, a multi-actor customer conception, where several actors partake in the overall purchase decision and an evolutionary notion of omnichannel practices in terms of their constitution and use as part of the overall evolution of a marketplace

Originality/value - The framework presented in this paper provides a map to take new research beyond its current boundaries and an audit tool to help managers identify their firm's current omnichannel situation, including limitations and opportunities for further development.
\end{abstract}

Keywords Channel strategy, Business model, Value creation, Customer, Co-evolution, Digital technology

Paper type Conceptual paper

\section{Introduction}

Surprisingly, the movement to omnichannel retailing has heretofore not been conceptualized as well, despite its growing importance in practice (Verhoef et al., 2015, p. 175).

(C) Ricardo Costa Climent, Darek M. Haftor and Soumitra Chowdhury. Published by Emerald Publishing Limited. This article is published under the Creative Commons Attribution (CC BY 4.0) licence. Anyone may reproduce, distribute, translate and create derivative works of this article (for both commercial and non-commercial purposes), subject to full attribution to the original publication and authors. The full terms of this licence may be seen at http://creativecommons.org/licences/by/4.0/legalcode

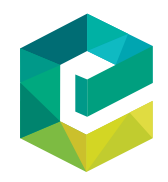

Received 12 July 2021 Revised 26 September 2021 Accepted 26 September 2021 
JEC

16,1

94

In Amazon's physical convenience stores, the Amazon Go App links customers to their user accounts to enable them to pay for items in store (Polacco and Backes, 2018). The store ceiling is covered with cameras, and the store shelves have weight sensors to detect the items chosen by each customer. If a customer takes a bottle of soda off the shelf, it is added to the customer's virtual cart. If the customer has a change of mind and places the bottle back, it will be removed from the customer's virtual cart (Ives et al., 2019). This kind of seamless integration of the customer experience across different channels and their touchpoints is called omnichannel (Cai and Lo, 2020; Verhoef et al., 2015). Omnichannel practices rely on modern digital technologies, along with agile supply chains (Akturk et al., 2018; Choi et al, 2001; Gao and Su, 2017; Kembro et al., 2018; Saghiri et al., 2017). All of these elements are synchronized to provide customers with a seamless customer journey. One of the main motivations for companies to invest in their omnichannel practices and explore the possibilities of digital technologies is the increasing competition and rapid commoditization of products (Hansen and Sia, 2015). Thus, firms seek to compete with new transaction capabilities rather than new products (Bourguignon et al., 2019). Although the business press has advocated for omnichannel practices for nearly two decades (Bell et al., 2014; Brynjolfsson et al., 2013; Piotrowicz and Cuthbertson, 2014), empirical studies of omnichannel practices have only recently appeared (Verhoef et al., 2015). Such studies signal two key shortcomings. First, companies fail in their omnichannel initiatives as they become overwhelmed by the inherent complexities involved (Lim and Srai, 2018; Larke et al., 2018). Second, omnichannel practices are poorly conceptualized. Therefore, there is little knowledge to ensure their successful development and management (Verhoef et al., 2015). Studies of omnichannel shopping experiences are mainly descriptive (Kazancoglu and Aydin, 2018), and further theoretical and empirical research is needed to elucidate how quality of experience affects customers' omnichannel purchase intent. Although explicit definitions provide initial insights, they are not sufficiently comprehensive.

To propose a conceptual overview of omnichannel practices, this paper addresses the fundamental question of what omnichannel practices actually are. The paper starts by providing a retrospective view of the emergence of omnichannel practices. It then inspects a set of representative definitions of omnichannel practices from scholarly research. This is followed by a more detailed inspection of omnichannel studies in terms of their focus of inquiry and theoretical lens. Together, this analysis reveals three key limitations of current conceptions of omnichannel practices:

(1) the conception of a customer as a single actor only;

(2) the lack of attention to the potential value created by omnichannel practices; and

(3) the predominantly static notion of omnichannel practices.

Section 2 provides remedies to these three limitations. The first remedy is a multi-actor conception of the customer. The second consists of four business model themes that represent sources of potential value creation through omnichannel practices. The third is an evolutionary view of omnichannel practices, whereby the approach must vary in response to various contextual changes. These three conceptions are unified into a framework that can support managers' efforts to advance omnichannel practices and scholars' design of inquiries into those practices. The framework presented in this paper is operationalized in terms of three research knowledge propositions to shape future validation. The proposed omnichannel framework advances the current omnichannel literature by describing practices with an underlying theoretical lens to expand the operational conception of omnichannel practices. This approach does justice to the reality of omnichannel. The paper ends with a discussion of these advancements and states the conclusions of this research. 


\section{Omnichannel research and its limitations}

This review develops a coherent conceptual and theoretical profile of current omnichannel practices, highlighting several limitations. After a brief overview of the origins of omnichannel practices, a set of definitions of omnichannel practices are examined to identify key approaches and assumptions, and several studies of omnichanneling are reviewed for their theoretical objectives and contributions to knowledge.

\subsection{Origins of omnichannel practices}

The retail industry has been a forerunner in several business and operational developments that have eventually spread to other industries. One such area is the use of multiple customer-facing channels (Cao et al., 2020). In the pre-internet era, traditional stores were complemented with catalogues and mail order systems. Later, TV and telephone orders emerged, accompanied by direct door-to-door sales (Raymond and Tanner, 1994). Firms at that time typically specialized in the use of one channel such as stores or catalogues (Phan and Vogel, 2010). The advent of internet-based technologies in the 1990s gave rise to e-commerce firms. For some industries such as travel, the emergence of these firms marked a genuine transformation (Standing and Vasudavan, 2000). E-commerce removed the dilemma whereby brick-and-mortar stores had to choose between providing either rich information nearby or reaching the customer (Evans and Wurster, 1999). This transformation led to the competition of online versus offline businesses in various industries (Verhoef et al., 2015), producing at least two evolutions. First, many brick-and-mortar stores complemented their offline channels with e-commerce (Akturk et al., 2018). In response, firms with an online presence established an offline presence as well. This situation gave rise to multichannel commerce practices, where firms initially attempted to optimize each channel individually, often with different product ranges and different price strategies for each channel (Ailawadi and Farris, 2017). An example of a key research question in a multichannel setting is which channel is most profitable and under what conditions (Verhoef et al., 2015). Firms soon discovered, however, that customers' actual behavior differed from what was expected or desired. Many customers tended to use different channels for different parts of the customer journey, switching between channels during this journey. Yet firms had assumed that each channel would handle the full customer journey (Barwitz and Maas, 2018; Emrich et al., 2015). For example, in certain contexts, customers experience the real-life product (e.g. shoes) in a store. They then search for the cheapest provider online, where they buy the product (Bell et al., 2018). In other cases, the journey may start online, where customers discover a product and read referrals. They then visit the store to see the product and buy it.

The advent of powerful mobile digital technologies in the 2000s, the increased international harmonization of regulatory frameworks, continuing urbanization and the development of flexible supply chain technologies (Piotrowicz and Cuthbertson, 2014) have acted as enablers for firms' multichannel efforts. These efforts soon evolved into crosschannel practices. Firms' use of different channels became coordinated, an example being when the same campaign is synchronized across several channels (Cai and Lo, 2020). Digital technologies not only offer the possibility to channel information and information-based products to customers but also provide other enabling capabilities to respond to customers' actual channel behavior (Fisher et al., 2019). One key affordance is the interaction between the customer and the firm. This interaction provides an inexpensive collection of volumes of customer data points throughout the customer journey. These data points provide a more comprehensive understanding of customers, which can then be used to customize offerings on an individual basis (Galipoglu et al., 2018). A second more profound affordance is the synchronization of content across different channels. Digital technology enables the transfer 
JEC

16,1

96

of information not only between the firm and the customer but also between different channels for each individual customer (Henning-Thurau et al., 2010).

Thus, firms can establish omnichannel practices where customers have a fully synchronized and seamless experience throughout the customer journey, regardless of which channels they choose (Hajdas et al., 2020). A customer's journey may start with a message on Facebook advertising a special offer - for example, an Italian suit. The customer goes to the firm's app, which provides details of the offer and lets the customer book an appointment at the physical store to choose the suit and have it fitted. Later, in the store, the customer interacts with a sales representative who is fully up-to-date on the customer's profile and the stage of this particular customer journey. Once the suit has been fitted, the customer agrees to pick it up an hour later. In the meantime, however, the customer has a change of mind and uses the app to order home delivery for the same evening.

A chief motivation for firms to invest in their omnichannel practices and explore the affordances of digital technologies is the ever-increasing competition and rapid commoditization of products (Hansen and Sia, 2015). Thus, firms attempt to compete with new transaction capabilities rather than with new products (Bourguignon et al., 2019). A customer may obtain the same kind of wine or shampoo at the same price but more conveniently from Provider A than from Provider B. At the same time, establishing and managing omnichannel practices is one of the most complex operational endeavors for a firm (Larke et al., 2018). For example, Lim and Srai (2018, p. 1735) notes that omnichannel practices require complex trade-offs between delivery responsiveness, product variety, and convenience. Successful omnichannel practices therefore require the management of a firm to govern its operations with surgical precision because nearly all parts of its operations must be synchronized for real-time control of consistency and a seamless customer experience (Larke et al., 2018). This synchronization covers sourcing and the supply chain for both forward and reverse flows, marketing, sales and after-market, with technology, legal, people, skills, culture and financial aspects. Because of the inherent complexities, some commentators suggest that it is easier to build an omnichannel practice from scratch than to transform an existing structure to omnichannel (Galipoglu et al., 2018). A number of empirical studies have aimed to provide an understanding of these complexities by identifying their underlying mechanisms, successes and hindrances (Cai and Lo, 2020). This research is now examined, with a focus on the assumptions of what omnichannel practices actually entail.

\subsection{What are omnichannel practices?}

One way to initiate research on a novel domain is to study the explicit definitions of the core research phenomenon in that domain (Bhaskar, 1997). Table 1 lists a selection of scholarly definitions of omnichannel practices. There is a somewhat surprising degree of uniformity across these definitions, given the newness of this domain. Structurally, omnichannel practices are conceived in terms of a customer who interacts with several channels offered by a provider, such as a firm. Functionally, the customer is able to switch between the provided channels throughout the whole purchase journey. The implicit purpose of omnichannel practices is thus to provide customers with a seamless buying experience, regardless of which channel is used. Omnichannel practices thereby offer greater convenience than cross-channel, multichannel or single-channel practices (Verhoef et al., 2015). The definitions examined here reveal the explicit customer-centric view underpinning omnichannel practices. Anticipating the subsequent investigation, we draw attention to the fact that none of the definitions offers a rationale or justification for why a firm should invest in and pursue omnichannel practices. So why should firms offer more convenient 


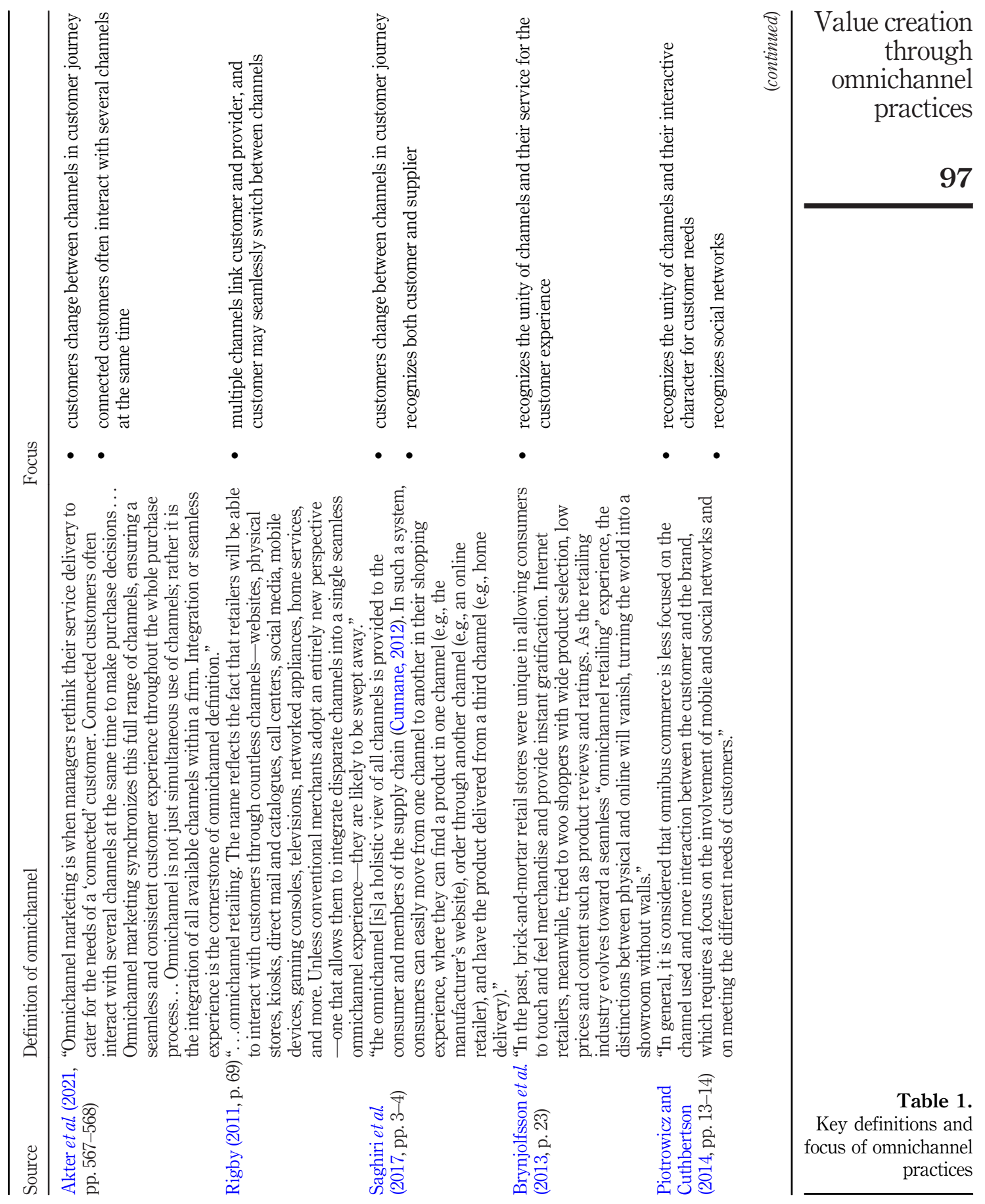


JEC
16,1

98

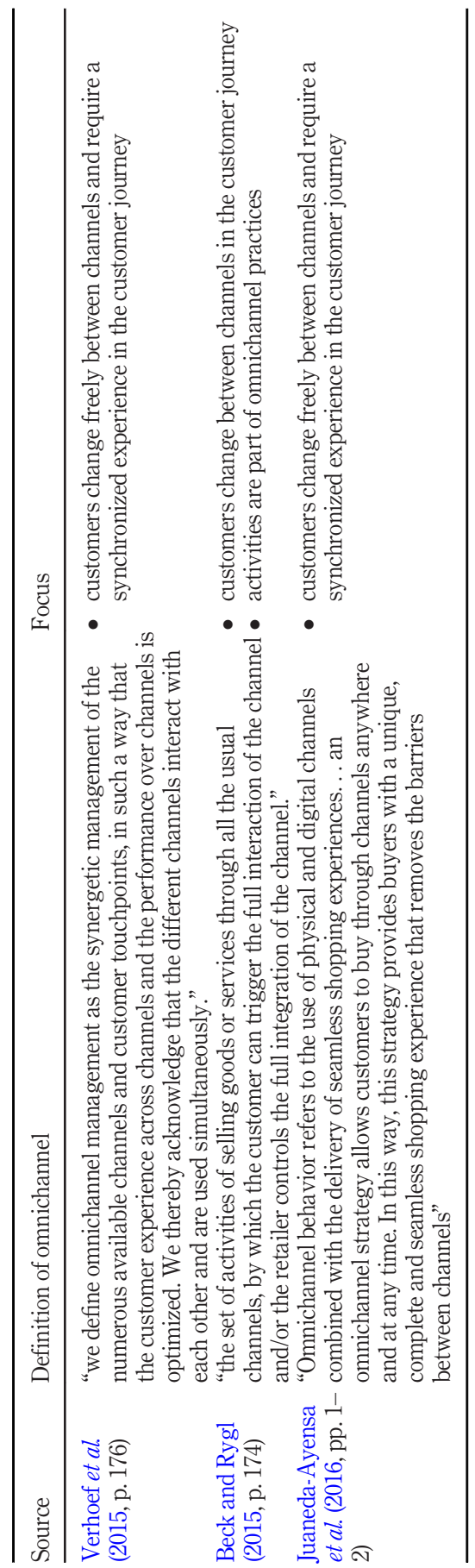

Table 1. 
customer experiences? What is the potential value that may be generated, and who benefits from this value? This finding is remarkable because investment in establishing omnichannel practices is substantial, and success is challenged by their inherent complexities. The unspoken assumption is that firms that invest in omnichannel practices will do better than firms that do not. This assumption has received some initial empirical support (Cai and Lo, 2020; Chen et al., 2018; Verhoef et al., 2015). However, this evidence does not explain why firms would have greater success when using omnichannel practices. This question is addressed below.

While explicit definitions offer an initial understanding, they are not necessarily comprehensive. They therefore do not properly reflect the actual research that has been conducted. Accordingly, we turn our attention to the key empirical studies of omnichannel practices.

\subsection{Omnichannel studies}

By investigating the key studies of omnichannel practices, we can identify the assumptions and conceptions of omnichannel practices. We explore each study's theoretical foundations and contribution to research on omnichannel practice. This approach provides a fundamental understanding of omnichannel practices. Table 2 provides an overview, and Appendix provides a more detailed summary of these studies.

Studies on omnichannel shopping experience are mainly descriptive (Kazancoglu and Aydin, 2018), and further theoretical and empirical research efforts are needed to uncover how the quality of experience affects customers' omnichannel shopping intention. In addition, prior research has studied omnichannel customer experience in a piecemeal fashion, focusing on perspectives of channel integration (Li et al., 2018; Shen et al., 2018), touchpoint management (Homburg et al., 2017), device quality (Rodrígueztorrico et al., 2017), information architecture (Burford and Resmini, 2017) and so on.

A quick inspection of Table 2 shows that the dominant concern is the customer's choice of channel or the customer's preference for omnichannel over multichannel. The predominant focus on omnichannel is concerned with a single individual's behavior and the factors that condition the choice of channel. Examples of these factors include attitudes and experience, information, and the source of this information. This finding is somewhat unexpected because a key idea of omnichannel practices is to go beyond the customer's choice of channel. The idea is that all channels together offer an omnipresent experience (Bell et al., 2014; Brynjolfsson et al., 2013; Shi et al., 2020; Silva et al., 2020).

After inspecting these studies, the following three key insights arise. These insights are addressed in Section 2 of this paper. First, these studies conceive the customer as an individual (a single human actor), not several individuals, an organization or a machine. This conception is unsurprising because omnichannel practices have been developed in the retail industry, where customers are individual human actors. This individual-based conception of customers is also a limitation to understanding the complexities of omnichannel practices. Buying decisions, when regarded as processes, are often undertaken by several interacting individuals. This situation also occurs in retailing, such as when someone advises a friend on the choice of suit.

A second insight here is the implicit core assumption of omnichannel studies that omnichannel practices make customers' buying processes more convenient. Accordingly, customers are expected to prefer to acquire products from omnichannel-equipped firms than from others. This customer convenience, or efficiency, would constitute a source of value creation. Surprisingly, however, the omnichannel literature does not explicitly elaborate on the value created by omnichannel practices, even though establishing these practices

\section{Value creation through omnichannel practices}

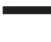


JEC
16,1

100

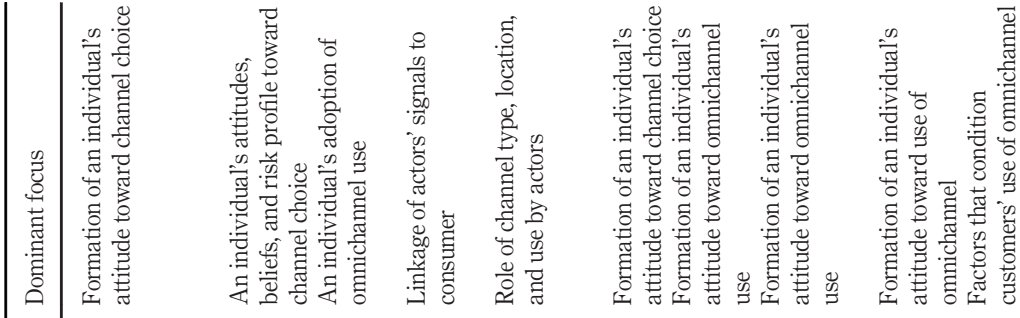

Table 2.

An overview of the foundations of the core empirical studies of omnichannel practices $\frac{\sqrt{1}}{\frac{1}{1}}$

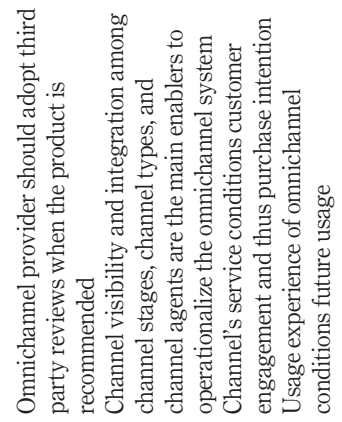

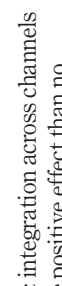

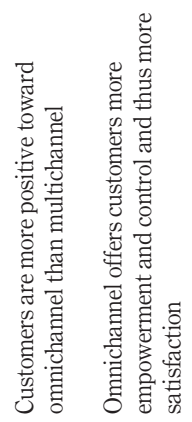

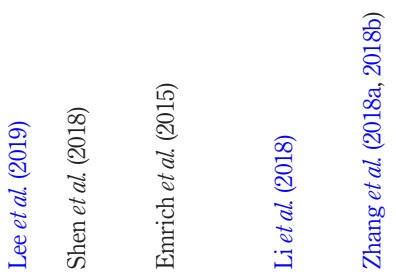

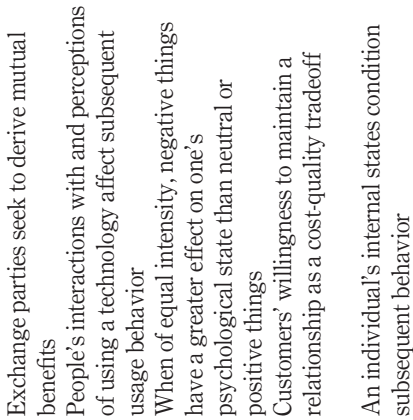

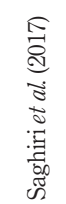

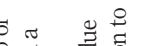

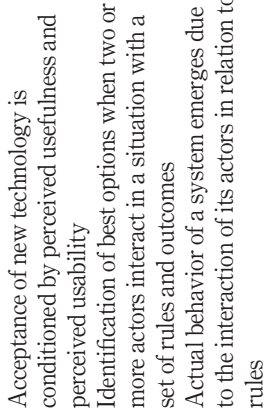

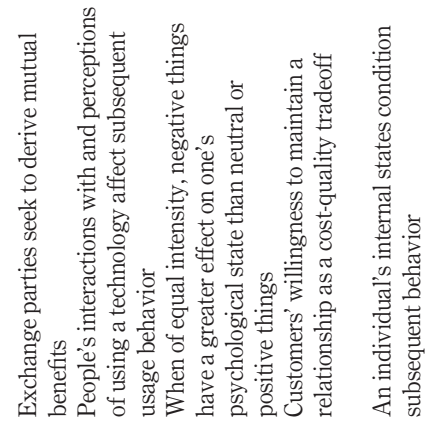


requires major efforts by firms (Brynjolfsson et al., 2013; Bell et al., 2014). Value creation is a chief motivation for such efforts and is therefore conceptually developed in this paper.

A third insight is that the conception of omnichannel practices is predominantly static. While several studies explain that omnichannel practices can be regarded as an evolution from multichannel and cross-channel practices, omnichannel practices are mainly conceived as stable. An alternative view, which is proposed and detailed here, is to regard omnichannel practices in evolutionary terms as they co-evolve with other factors of business behavior.

\section{Reconceptualization of omnichannel practices}

We propose to remedy these three key limitations of the current conceptualizations of omnichannel practices as follows.

\subsection{The customer: from a single-actor to a multi-actor conception}

Omnichannel practices have been championed and advanced over the past two decades by the retail industry (Brynjolfsson et al., 2013). In this industry, the customer, who is targeted by a firm's omnichannel operations, is considered to be a single actor. This single human individual conducts the whole purchase process (Bell et al., 2014), such as buying clothes, cosmetics or food. This single-actor notion is shown in the earlier review of contemporary notions of omnichannel and empirical studies. These studies predominantly use theoretical lenses originating in psychology. While such studies are highly informative, they are also reductionist in the sense that they reduce the concept of a customer to a single human actor.

Instead, the long-established notion of a purchase decision process (Engel et al., 1968; Howard and Jagdish, 1969) shows that many purchase decisions are conducted by multiple actors. These multiple actors may be several persons, several organizations or even several countries, depending on the context (Wadman and Hütt, 2004). A casual empirical illustration of this multi-actor notion is the family of a child. A mother and father visit a food market. The child asks her parents for an ice cream. The mother decides on fruit for the child, while the dad pays for it. In another context, Intel's seminal rebranding of its computer processors, from a business-to-business product to a business-to-business-and-consumer product, was based on the realization that the consumer-customer acts as a pulling force on the laptop assemblers who buy the processors from Intel (Norris, 1993).

Thus, we consider the five phases of the traditional purchase decision process as follows:

(1) problem or need recognition;

(2) information search;

(3) evaluation of alternatives;

(4) purchase decision and action; and

(5) post-purchase behavior (Engel et al., 1968; Howard and Jagdish, 1969).

For our purposes, we may assume a simplified process of just three phases: pre-purchase, purchase (decision and action) and post-purchase. Our key message here is that while the purchase literature has long recognized that the purchase decision process often involves multiple actors (Bearden and Etzel, 1982), the literature on omnichannel practices disregards this point and reduces the notion of a customer to a single human actor. To do justice to reallife purchase experiences, we propose a reconceptualization of the limited single-actor definition of omnichannel to a definition that also allows for multi-actor customers.

The literature shows that purchase processes are often conducted by multiple actors with a varying degree of purposeful synchronization between these actors' purchase activities in the process (Bearden and Etzel, 1982). Recent research has shown that actors can constantly

\section{Value creation through omnichannel practices}


move between purchase phases, which leads to nested and dynamic purchase processes that lack an invariant structure (Karim et al., 2015; Srinivasa et al., 2016). Thus, firms that aim to establish omnichannel practices must consider at least two fundamental questions. First, which actors are or will be involved in the purchase of the firm's offering? For example, is it always one, two or three, or is it mostly one and sometimes two actors or some other configuration? Second, what is the degree of deliberate synchronization between the involved actors? That is, do the two actors who conduct the purchase process have the same objectives, decision criteria and decision information? Or do the actors have divergent interests, objectives, criteria and information, despite all determining the final purchase decision? For example, many employers provide employees with a company car as part of their compensation package. The employer provides a certain cost frame and a range of car brands, while employees decide which of these cars they want. The two actors co-decide the purchase of the product. However, if the employee is unhappy with the listed car brands and asks the employer to include another brand within the cost frame, then there is a semisynchronized purchase decision process involving two key actors.

We propose that omnichannel practices require a synchronization of the interaction between one or more actors who constitute the customer and two or more channels that target the actor or actors who constitute the customer and who conduct various activities within the purchase decision process and beyond. Failure to identify this complexity may lead firms to invest heavily in omnichannel practices that target only one of several actors who together constitute the customer. Even worse, firms may launch different unsynchronized channels targeting different actors constituting the customer. A firm that provides cars for leasing can target its omnichannel toward individuals employed at firms that offer company car schemes. Such channels may be TV and newspapers adds, web and social media adds and physical stores. These channels all provide a deliberate and fully synchronized pre-purchase interaction experience. The car-providing firm may also target the employer with omnichannel through, say, dedicated web messages, emails and sales rep calls. These channels all provide the employer with incentives to present the firm's car brands as first-choice alternatives and may increase traffic through the omnichannel routes that target employees. The two actors' characteristics, situation and interests condition the design and use of omnichannel to target each actor and the synchronization of the two omnichannel solutions and content. The same is true of activities in the purchase decision phase and the post-purchase decision phase. For instance, an employee who leases a car may need to change its tires. This service may be offered as a subservice e-booking solution that is synchronized with the information received by the employer, who accepts the order as legitimate.

\subsection{Business model as the context for omnichannel value creation}

The second reconceptualization of omnichannel proposed here focuses on value creation. The above inspection of omnichannel research shows a surprising lack of discussion of why a firm should invest in such costly initiatives that are exposed to high risks owing to their inherent complexities (Frederick et al., 2018; Larke et al., 2018). An implicit assumption in the reviewed empirical studies is that omnichannel offers customers greater convenience than multichannel or single-channel practices. This point is further elaborated below.

Of the studies reviewed here, only one explicitly addresses the potential strategic value of omnichannel practices. Brynjolfsson et al. (2013) take an industrial organization perspective Besanko et al. (2010) to derive some potential strategic benefits of omnichannel practices. Their message is that omnichannel practices reduce the barriers to entry to a marketplace by eliminating the geographical barrier and customers' ignorance through higher customer 
attention. Their recommendations include attractive product pricing, the avoidance of direct product price comparison and a focus on niche products. Their recommendations are based on Porterian product market strategies (Porter, 1985). While their recommendations seem reasonable, they limit the context of omnichannel practices. A key driver of firms' investment in omnichannel practices is the high level of product commoditization, the inability to differentiate products and the consequent price wars. In such situations, firms that pursue omnichannel do so to overcome these challenges by focusing on transaction activities. It is still the same pair of shoes, shampoo or bottle of wine as that provided by many other firms, yet the omnichannel-endowed firm interacts with customers in a more convenient manner than the alternative providers, which attracts customers. We propose sources of value creation through omnichannel practices as opposed to those derived from product market strategies. We propose sources of value creation that originate in the way a firm conducts its business and, by extension, in its business model.

The notion of a business model developed around the year 2000 in response to the unparalleled value creation by various firms based on the use of digital technologies (Amit and Zott, 2001). Scholars realized that the conventional theoretical lenses of managerial economics, strategic management and entrepreneurship were insufficient on their own to account for such value creation (Amit and Zott, 2001). There is a consensus that a firm's business model is an "architecture of value creation, delivery, and capture mechanism" (Teece, 2010, p. 172). More specifically, according to the notion of a business model, value creation and appropriation are conceived as a firm's boundary-spanning activity system, conducted by a set of actors linked with transaction mechanisms (Amit and Zott, 2001; Foss and Saebi, 2017; Writz et al., 2016). It is thus the way a firm conducts its business that may activate various sources of value creation. These sources of value creation complement the product-based value creation expounded in the industrial organization literature (Besanko et al., 2010). A seminal case study details how one and the same product (a photocopy machine provided by the US firm Xerox) failed in one business model, through selling, yet succeeded in another, through leasing (Chesbrough and Rosenbloom, 2002). Crucially, the architecture of a business model can be configured to pursue one or several themes to create value. Four such themes have been proposed: novelty, efficiency, complementarity and lockin (Amit and Zott, 2001; Kulins et al., 2016; Zott and Amit, 2007, 2008). Business model themes co-determine variation in firm performance and thus complement industry-specific and firm-specific effects on firm performance (McGahan and Porter, 2002; Rumelt, 1991; Hawawini et al., 2003).

3.2.1 Novelty as a source of value creation through omnichannel. The novelty business model theme refers to new ways of doing business (Amit and Zott, 2001; Zott and Amit, 2007) in terms of the configuration of actors, activities and transactions that constitute a business model's architecture and differentiation from peers (Amit and Zott, 2001; Zott and Amit, 2007). An example is AirBnB's disruption of the lodging market, where a novel transaction mechanism links available accommodation with guests. The source of value creation in novel business models is Schumpeterian innovation (Schumpeter, 1934). This form of innovation exploits a latent market need, attracts customers through its novelty and thereby realizes entrepreneurial rents Schumpeter (1942) until being imitated by followers. As an illustration, Dell's novel internet-mediated "make-to-order and ship-to-customer" business model was launched in the mid-1990s and then imitated by followers (Kraemer et al., 2000). In the same sense, an introduction of a novel omnichannel configuration (i.e. the channels included and the way they are integrated) represents a novel business model if it is novel in some sense and has a good market fit. It is then likely to attract additional customers, compared with the preomnichannel situation. It thereby constitutes a source of value creation for both customers and

\section{Value creation through omnichannel practices}

103 
providers. Recalling the multi-actor notion of a customer, a largely unexplored source of novelty, and therefore value creation, is omnichannel that targets several actors that constitute the customer. This scenario is exemplified by the previous illustration of a firm that leases cars and targets both employees and employers. In our casual experience, these opportunities are largely unexplored.

3.2.2 Efficiency as a source of value creation through omnichannel. The efficiency business model theme refers to a comparatively low resource use by the actors involved in business model realization (Amit and Zott, 2001; Zott and Amit, 2007). Efficiency is implicitly reflected in the reviewed omnichannel studies (Cai and Lo, 2020; Verhoef et al., 2015). Efficiency is what drove the growth of the streaming music provider Spotify. Spotify channels endless volumes of music anywhere, anytime, more conveniently than Apple's relatively cumbersome file downloading transaction. The following example illustrates efficiency. A customer wishes to purchase wine. The customer conducts this purchase while navigating across several fully integrated channels providing a consistent, boundaryless experience. This customer will find it easier, and thus more efficient, than a second customer who must switch between channels. This second customer must manually transfer information (such as login details, customer identification and re-briefing a telephone agent) and must therefore restart the whole purchase process each time the channel is changed. Similarly, certain purchase processes involve several actors. One example is the car leasing scenario described earlier. This purchase process will become more efficient for those involved if the channels are synchronized into a deliberate, seamless experience for all actors. In that example, the actors are the car leasing provider, the employer that legally contracts the leased cars and the employee. As mentioned above, our casual experience suggests that this inter-actor synchronization is an unexplored opportunity in current omnichannel practices.

3.2.3 Complementarity as a source of value creation through omnichannel. The complementarity business model theme relies on various ways of bundling or synchronizing offerings (goods or services), activities or resources, including technologies (Amit and Zott, 2001; Zott and Amit, 2007). It generates value through complementarity, or synergy, when Factor A generates more value in the presence of Factor B than on its own or in the presence of Factor C (Ennen and Richter, 2010; Milgrom and Roberts, 1995). The complementarity business model theme that relies on bundling offerings is exemplified by intermediaries such as travel agencies, which offer complementary travel services (e.g. several modes of transport, a range of accommodation, insurance, travel guides and recommendations). By definition, omnichannel realizes value through the combination of several channels, as does multichannel. However, the omnichannel channels are synchronized to provide one deliberate, consistent customer journey. A core question is what channels should be included in the omnichannel to generate value through their complementarity? For example, if a firm has a web shop channel only, a decision may be to launch a dedicated App for smartphones and tablets, to open physical stores or to do both. The answer depends on the context, cost and benefits. However, it is crucial to understand the complementarity value of including an additional channel in the omnichannel experience. A second central consideration is that the complementarity value may also be generated from omnichannel solutions where several actors are involved in the purchase decision process, as illustrated above with the car leasing example. If the leasing firm has omnichannel solutions for the employer (the leasing contractor), it may realize complementary value by also providing omnichannel solutions to the employee who uses the car.

3.2.4 Lock-in as a source of value creation through omnichannel. Finally, the lock-in business model theme (Amit and Zott, 2001) is realized by discouraging actors of a business 
model (e.g. customers, mediators, partners and suppliers) to migrate to a competitor. Lock-in can be achieved through sunk costs (Parayre, 1995), such as when suppliers invest in product development that meets a customer's unique needs but that is less useful to other customers. It is also illustrated through the activation of network externalities (Church and Gandal, 1992; Katz and Shapiro, 1985, 1992; Sheremata, 2004; Suarez, 2005) such as the use of social media like Facebook. The more people use it, the more value it provides to its members, who become discouraged from migrating to an alternative.

Another category of network effects are data network effects, where the more an offering is used, the more its provider can learn from the data generated by this use. The data can then be exploited to improve and develop the offering and thereby generate more value for users (Gregory et al., 2020).

A firm's omnichannel practices may activate lock-in through both sunk costs and network externalities. For example, as a customer actor becomes used to a particular omnichannel setup, new habits are established, making it challenging to change to another provider that offers a similar omnichannel solution. The customer actor spends time setting up an account with login and credit card details and then learns to use the specific omnichannel. The question is therefore, why go through this process again with another provider if there is no substantial difference and hence no noticeable benefit? To encourage such a switch, a competitor has two options. First, it can innovate substantially in its omnichannel experience, making it truly more attractive. The customer may thus be willing to sacrifice the effort invested in the current omnichannel provider. Alternatively, a competitor can adopt alternative product market strategies such as product differentiation, niches, early launches and pricing (Porter, 1985).

Network effects may be activated in several ways by omnichannel solutions. One way is to gather and analyze customer data to identify patterns. For example, firms today offer customized product offerings based on customers' transaction history. As an illustration, a bookshop proposes a new book title based on the unique history of books that have been bought by a given customer. Similarly, the customer's specific patterns of omnichannel use generate insights that may be used for future customization of omnichannel experiences. For example, a food provider may present its food as a romantic dinner in film format on the smartphone App or may show it with its nutrition tables, depending on the customer profile. However, the firm is still selling the same prawns and mayonnaise. A new competitor lacks detailed historical data and is therefore unable to provide the same degree of customization of omnichannel experiences, which discourages the customer from switching to the competitor, assuming all else is equal.

The provision of omnichannel solutions to several customer actors, as illustrated above with the car leasing example, may also activate network effects and thereby the lock-in business model theme. To continue with the same example, we assume that the employer contracts two car leasing providers. Each provides a similar portfolio of car brands. Provider A has a multi-actor omnichannel solution in place, whereas Provider B offers an omnichannel solution for only one customer actor: the employer. Employees who have had a leased car for three years and are ready to change to a new one are familiar with their omnichannel solution for the operational handling of the car. If satisfied, they will select it again rather than choosing Provider B, assuming that all else is equal.

Finally, the four sources of value creation of a business model may interact and reinforce each other. Certain theme interactions make a business model more difficult to compete with (Amit and Zott, 2001; Zott and Amit, 2007). Searching for these four sources of value creation in studies of omnichannel practices shows that only the efficiency source has been
Value creation through omnichannel practices 
implicitly examined, whereas the three remaining sources have received no attention. They hence have unexplored potential.

\subsection{Toward a co-evolutionary notion of omnichannel practices}

The above elaboration of the proposed four sources of value creation for omnichannel practices implies a temporal dimension of a business model and therefore of omnichannel practices because business model themes may change over time. A firm that launches a new business model and thereby activates novelty may eventually have a number of imitators. The entrepreneurial firm must react and transform its business model, possibly activating other sources of value creation such as complementarity and eventually lock-in. These sources will be followed by competitors' actions. Such a co-evolution of business models steers us toward the literature on evolutionary economics.

Neoclassical economics relies on the assumption of stability, equilibrium and optimal decision making of economic agents. Evolutionary economics holds that human decision making and behavior is seldom optimal but is instead biased and restricted. Humans are motivated, are capable of imagination and are able to learn. All of these facets drive innovation, change, competition and thus evolution. Innovation offers a temporary monopoly over the use of newness. However, if successful, it will soon be copied and surpassed (Nelson et al, 2018). In short, evolutionary economics views an economy as always in motion, much like the context of cultural evolution (Mesoudi, 2011). Studies have shown that the success of a firm is partly conditioned by its industry (Rumelt, 1991). The orthodox understanding of an industry is static and focuses on equilibrium. The assumption is that a firm's key task is to compete through price and productivity optimization to give buyers value (Besanko et al., 2010). That view, however, disregards novelty and radical change. Evolutionary economics views such an understanding as restrictive because experience shows that new industries emerge, change, and decline (Nelson et al., 2018). Industry evolution generates path dependencies for actors, which condition firm success. Evolutionary economics therefore holds that understanding a firm's success requires an understanding of the firm's context and evolution (Nelson et al., 2018).

Crucially, however, studies of industries and the way they change focus on the innovation of products and services, production processes, organizations, governance and input sourcing (Casadesus-Masanell and Zhu, 2013). There is no research on how industries transform because of business model innovation through omnichannel, even though the empirical evidence in our review suggests that such an evolution occurs. A single channel evolves into multiple offline channels. Through e-commerce, this then evolves into multichannel blending of offline with online. This has now evolved into initial omnichannel practices, which largely focus on one customer actor only and disregard the various value creation sources. To remedy the current static view of omnichannel practices, we propose a co-evolutionary view based on the theory of evolutionary economics. Such a view accounts for the experiences of the major transitions such as multichannel to omnichannel and beyond. Equally importantly, the co-evolutionary view may also shape our understanding of the dynamics of a given firm's omnichannel practices from several perspectives. One such perspective is when a firm in a given marketplace introduces its new omnichannel solution and thereby succeeds in attracting new customers and growing its market share. Competitors will be unlikely to wait long before imitating through similar omnichannel practices. Hence, they co-evolve. Based on its unique first-mover experience, the pioneering firm will then further develop, hence co-evolving. It will do so by updating its omnichannel through, say, the introduction of additional channels such as sales in a digital marketplace such as Amazon. This shift may again be imitated by followers. Other possible sources of 
change are the advent of new technologies such as augmented reality (Nelson et al., 2018) that enable the focal firm to launch novel omnichannel solutions with new kinds of customer experiences. Yet another source of change may be institutional. New regulations, customer taste changes or migration from a particular social platform to another may force the evolution of omnichannel configuration and content. Still another change may be to include, in a stepwise fashion, additional customer actors. For instance, in the pharmaceutical industry, it may be a patient, the relatives of the patient, a physician or an insurance company that pays for pharmaceuticals. Recalling the above elaboration of value creation sources, the evolution of omnichannel may manifest changes of the activation of such sources. For example, the pioneering omnichannel firm may start with the novelty source, evolve to complementary and then activate lock-in once it has managed to generate large customer transaction data sets. These data sets in turn enable the firm to customize the experiences and uses of its omnichannel solution.

\subsection{Omnichannel as an evolution of business model themes with multi-actor customers}

This development of the conception of omnichannel practices may be synthesized into a framework, as illustrated in Table 3. The typical customer journey, as represented by the customer purchase decision process (Engel et al., 1968), is articulated in terms of pre-purchase activities, purchase activities and post-purchase activities. Each of these activities may be executed by one or several actors that constitute the customer of a focal firm (A, B, C or D in Table 3$)$. These customer actors may in turn be targeted by a set of individual channels $(1,2$, 3,4 or 5 in Table 3 ). These individual channels are unified into one omnichannel solution by a focal firm. As an illustration only, a specific mix of channel use at one time ( $t 1$ in Table 3 ) may activate, for example, the novelty $(\mathrm{N})$ theme of the firm's business model. Another mix of channels at a later time ( $\mathrm{t} 2$ in Table 2) means an omnichannel practice that activates, for example, the complementary (C) theme of the firm's business model. Based on this development, the following knowledge propositions are derived:

\section{P1. Single-actor synchronization.}

Firms that pursue omnichannel synchronization for a single customer actor and thereby activate one or several business model themes will, on average, succeed more than firms that pursue omnichannel synchronization without activation of one or several business model themes through their single-actor omnichannel, all else being equal:

\section{P2. Multi-actor synchronization.}

Firms that pursue omnichannel synchronization for multiple customer actors and thereby activate one or several business model themes will, on average, succeed more than firms that pursue omnichannel synchronization without activation of one or several business model themes through their multi-actor omnichannel, all else being equal:

P3. Multi-actor versus single-actor view.

Firms that pursue omnichannel synchronization for multiple customer actors and thereby activate one or several business model themes will, on average, succeed more than firms that pursue omnichannel synchronization for one customer actor only, ignoring other customer actors, all else being equal.

\section{Value creation through omnichannel practices}


JEC
16,1

108

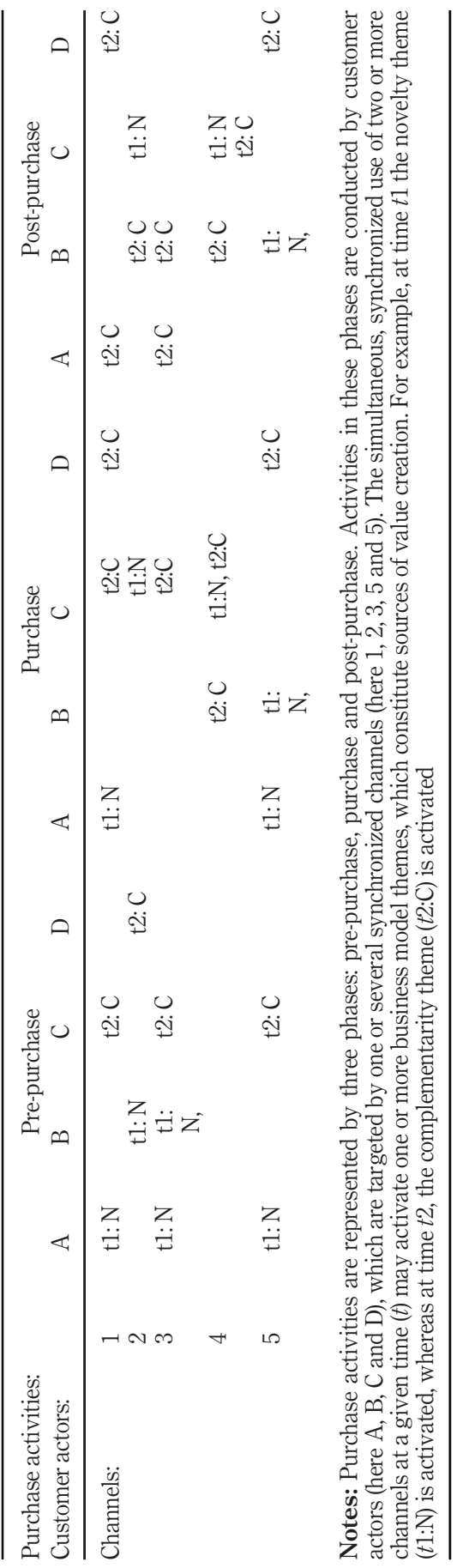

Table 3.

A Schematic illustration of the conception of omnichannel practices 


\section{Discussion and conclusions}

In certain sectors, products are commodities, as is the case in the manufacturing industry. This situation leads to price-based competition. In these sectors, firms compete by enhancing their transaction operations to channel products to customers. Omnichannel is the gold standard. It represents a firm's seamless integration of multiple channels and customer touchpoints. The aim is to deliver a consistent, progressive customer experience throughout the purchase decision process, regardless of the channel the customer uses at any given stage of the process. Recent empirical research signals that firms' efforts to through omnichannel practices develop and manage omnichannel practices fail owing to the inherent complexities of such operations (Frederick et al., 2018; Larke et al., 2018). A chief reason is the limited conceptual foundations of what omnichannel practices are and how they create value. We propose remedies to these conceptual limitations. First, we advance the conception of the customers who are targeted by omnichannel practices. The current single-actor customer is replaced by a multi-actor customer. Second, we articulate four distinct sources of value creation that are potentially generated by omnichannel practices. We thereby move beyond the current notion of convenience as the implicit justification for firms to establish omnichannel practices. Third, the current static notion of omnichannel practices as an entity are replaced with the notion of evolutionary processes. In these evolutionary processes, the structure and content of omnichannel co-evolve in their interaction with other contextual factors, such as new technology, institutional change and competitors' initiatives. Fourth, the three conceptual advancements are integrated into a coherent conceptual framework. This framework can help managers both in their auditing of existing omnichannel practices and in their design and road-mapping of new advanced practices to outperform competitors. The proposed framework draws managers' attention to three commonly ignored ideas: that omnichannel practices may target several customer actors rather than only one; that there are several sources of value creation that may be activated by omnichannel practices to generate success; and that any omnichannel efforts must be regarded in evolutionary and longitudinal terms, with long-term plans, budgets, and governance.

The proposed conceptual framework for omnichannel practices is operationalized by three knowledge propositions aimed to guide future research on omnichannel practices. Other questions still need addressing. For example, to what extent does the use of omnichannel generate value from the investment it requires? Furthermore, what are the specific sources of this value creation in contexts where purchase decisions are made by a network of actors and evolve over time through interactions with key contextual factors? This view represents a significant broadening of omnichannel research. Studies in this area have been limited to investigations of behavioral decisions by a single, individual customer actor with regard to channel preferences. Consequently, a shift is required from psychologyrooted theories toward theoretical lenses from other disciplines such as entrepreneurship, economics and strategic management.

The theoretical framework proposed here has certain limitations, which also represent opportunities for further research. One such limitation is the need to test the framework empirically, and another limitation is to account for the interactions between a firm's use of omnichannel and the product market strategies the firm uses as distinct sources of value creation.

A detailed, tested and broad theoretical basis must be developed to build knowledge of omnichannel practices and their successful implementation. Development of such a basis invites research on how to quantify the economic value of omnichannel practices and the risks that retailers are exposed to during such a transformation. As Rigby (2011) explains, for most companies, transforming to omnichannel is a huge undertaking. Acting too slowly 
can cost them their position as leaders at a time when market share is changing rapidly. Conversely, acting too quickly may not give them time to test, learn and rectify.

So, is it worth all the effort? Successful omnichannel practices must first and foremost guarantee survival in a dynamic market. However, they must also benefit customers by satisfying their expectations and experiences. This customer benefit has been a mainstay throughout history whenever milestones such as the arrival of online sales and the invention of the smartphone have been reached. There has been a positive impact on person-to-person transfers. Grocery payments and mobile money providers have to continue to simplify the access to financial services (Museba et al., 2021).

Therefore, there is a need for progress in studying the real value created by omnichannel and the extent to which it can overcome the risks and complexities that omnichannel currently entails for retailers.

In addition, an in-depth study of customers' perceptions of the value that has been created would undoubtedly help entrepreneurs adapt their offerings and strategies to omnichannel. Omnichannel must generate customer trust through transparency and legitimacy to prevent customers from choosing the competition in their purchase processes. Complexities such as managing customer data and using personal information are sensitive issues that must be considered when connecting channels and enabling their use by customers without violating consumer privacy, which is protected by laws such as the general data protection regulation (GDPR) in the European Union.

A theoretical lens that offers a way of mitigating this risk is the use of $\mathrm{AI}$ in improving customers' perceptions of value. The data processing and automatic learning enabled by AI and large data sets helps firms match their offerings to clients' demands. This positive relationship between user value and the provider's ability to learn and improve offerings is moderated by factors such as prediction, legitimization, data management and user-centered design (Gregory et al., 2020).

\section{References}

Ailawadi, K.L. and Farris, P.W. (2017), "Managing multi- and omni-channel distribution: metrics and research directions", Journal of Retailing, Vol. 93 No. 1, pp. 120-135.

Ajzen, I. (1991), "The theory of planned behavior", Organizational Behavior and Human Decision Processes, Vol. 50 No. 2, pp. 179-211.

Akter, S., Hossain, T.M.T. and Strong, C. (2021), "What omnichannel really means?", Journal of Strategic Marketing, Vol. 29 No. 7, pp. 567-573.

Akturk, M.S., Ketzenberg, M. and Heim, G.R. (2018), "Assessing impacts of introducing ship-to-store service on sales and returns in omnichannel retailing: a data analytics study", Journal of Operations Management, Vol. 61 No. 1, pp. 15-45.

Amit, R. and Zott, C. (2001), "Value creation in e-business", Strategic Management Journal, Vol. 22 Nos 6/7, pp. 493-520.

Barwitz, N. and Maas, P. (2018), "Understanding the omnichannel customer journey: determinants of interaction choice", Journal of Interactive Marketing, Vol. 43, pp. 116-133.

Bearden, W.O. and Etzel, M.J. (1982), "Reference group influence on product and brand purchase decisions", Journal of Consumer Research, Vol. 9 No. 2, pp. 183-194, doi: 10.1086/208911.

Beck, N. and Rygl, D. (2015), "Categorization of multiple channel retailing in multi-, cross-, and omnichannel retailing for retailers and retailing”, Journal of Retailing and Consumer Services, Vol. 27, pp. 170-178.

Bell, D.R., Gallino, S. and Moreno, A. (2014), "How to win in an omnichannel world", MIT Sloan Management Review, Vol. 56 No. 1, p. 45. 
Bell, D.R., Gallino, S. and Moreno, A. (2018), "Offline showrooms in omnichannel retail: demand and operational benefits", Management Science, Vol. 64 No. 4, pp. 1629-1651.

Besanko, D., Dranove, D., Shanley, M. and Schaefer, S. (2010), Economics of Strategy, 5th ed., Wiley, New York, NY.

Bhaskar, R.A. (1997), A Realist Theory of Science, Verso, London.

Bourguignon, H., Gomes, R. and Tirole, J. (2019), "Shrouded transaction costs: must-take cards, discounts and surcharges", International Journal of Industrial Organization, Vol. 63, pp. 99-144.

Brynjolfsson, E., Hu, Y.J. and Rahman, M.S. (2013), "Competing in the age of omnichannel retailing", MIT Sloan Management Review, Vol. 54 No. 4, pp. 23-29.

Burford, S. and Resmini, A. (2017), "Cross-channel information architecture for a world exposition", International Journal of Information Management, Vol. 37 No. 6, pp. 547-552.

Cai, Y.J. and Lo, C.K. (2020), "Omni-channel management in the sharing economy era: a systematic review and future research agenda", International Journal of Production Economics, Vol. 229, p. 107729.

Cao, K., Xu, Y., Cao, J., Xu, B. and Wang, J. (2020), "Whether a retailer should enter an e-commerce platform taking into account consumer returns", International Transactions in Operational Research, Vol. 27 No. 6, pp. 2878-2898.

Casadesus-Masanell, R. and Zhu, F. (2013), "Business model innovation and competitive imitation: the case of sponsor-based business models", Strategic Management Journal, Vol. 34 No. 4, pp. 464-482.

Chen, Y., Cheung, C.M. and Tan, C.W. (2018), "Omnichannel business research: opportunities and challenges", Decision Support Systems, Vol. 109, pp. 1-4.

Chesbrough, H. and Rosenbloom, R.S. (2002), "The role of the business model in capturing value from innovation: evidence from xerox corporation's technology spin-off companies”, Industrial and Corporate Change, Vol. 11 No. 3, pp. 529-555.

Choi, T.Y., Dooley, K.J. and Rungtusanatham, M. (2001), "Supply networks and complex adaptive systems: control versus emergence", Journal of Operations Management, Vol. 19 No. 3, pp. 351-366.

Church, J. and Gandal, N. (1992), "Network effects, software provision, and standardization", The Journal of Industrial Economics, Vol. 40 No. 1, pp. 85-103.

Cunnane, C. (2012), "The 2012 omni-channel retail experience. Aberdeen group, January 2012", available at: www.yumpu.com/en/document/view/15386420/customer-centric-retailing-101customer-intelligence-and-stores (accessed 6 May 2019).

Emrich, O., Paul, M. and Rudolph, T. (2015), "Shopping benefits of multichannel assortment integration and the moderating role of retailer type", Journal of Retailing, Vol. 91 No. 2, pp. 326-342.

Engel, J.F., Kollat, D.T. and Blackwell, R. (1968), Consumer Behaviour, Holt, Reinhart and Winston, New York, NY.

Ennen, E. and Richter, A. (2010), "The whole is more than the sum of its parts - or is it? A review of the empirical literature on complementarities in organizations", Journal of Management, Vol. 36 No. 1, pp. 207-233.

Evans, P. and Wurster, T.S. (1999), Blown to Bits: How the New Economics of Information Transforms Strategy, Harvard Business School, Boston.

Fisher, M.L., Gallino, S. and Xu, J.J. (2019), "The value of rapid delivery in omnichannel retailing", Journal of Marketing Research, Vol. 56 No. 5, pp. 732-748.

Foss, N.J. and Saebi, T. (2017), "Fifteen years of research on business model innovation: how far have we come, and where should We go?”, Journal of Management, Vol. 43 No. 1, pp. 200-227.

Galipoglu, E., Kotzab, H., Teller, C., Hüseyinoglu, I.Ö.Y. and Pöppelbuß, J. (2018), "Omni-channel retailing research-state of the art and intellectual foundation", International Journal of Physical Distribution and Logistics Management, Vol. 48 No. 4, pp. 365-390.
Value creation through omnichannel practices 
Gao, F. and Su, X. (2017), “Online and offline information for omnichannel retailing”, Manufacturing and Service Operations Management, Vol. 19 No. 1, pp. 84-98.

Gregory, R.W., Henfridsson, O., Kaganer, E.A. and Kyriakou, H. (2020), "The role of artificial intelligence and data network effects for creating user value", Academy of Management Review, Vol. 46 No. 3, pp. 534-551.

Hajdas, M., Radomska, J. and Silva, S.C. (2020), “The omni-channel approach: a utopia for companies?”, Journal of Retailing and Consumer Services, p. 102131.

Hansen, R. and Sia, S.K. (2015), "Hummel's digital transformation toward omnichannel retailing: key lessons learned”, MIS Quarterly Executive, Vol. 14 No. 2, pp. 51-66, Article 3.

Hawawini, G. and Subramanian, V. and Verdin, P. (2003), "Is performance driven by industry-or firmspecific factors? A new look at the evidence", Strategic Management Journal, Vol. 24 No. 1, pp. 1-16.

He, Y., Xu, Q. and Wu, P. (2020), "Omnichannel retail operations with refurbished consumer returns", International Journal of Production Research, Vol. 58 No. 1, pp. 271-290.

Henning-Thurau, T., Malthouse, E.D.C., Friege, C., Gensler, S., Lobschat, L., Rangaswamy, A. and Skiera, B. (2010), "The impact of new media on customer relationships", Journal of Service Research, Vol. 13 No. 3, pp. 311-330.

Homburg, C., Jozić, D. and Kuehnl, C. (2017), “Customer experience management: toward implementing an evolving marketing concept", Journal of the Academy of Marketing Science, Vol. 45 No. 3, pp. 377-401.

Howard, J.A.S. and Jagdish, N. (1969), The Theory of Buyer Behaviour, Wiley, New York, NY.

Ives, B., Cossick, K. and Adams, D. (2019), “Amazon go: disrupting retail?", Journal of Information Technology Teaching Cases, Vol. 9 No. 1, pp. 2-12, doi: 10.1177/2043886918819092.

Juaneda-Ayensa, E., Mosquera, A. and Sierra Murillo, Y. (2016), "Omnichannel customer behavior: key drivers of technology acceptance and use and their effects on purchase intention", Frontiers in Psychology, Vol. 7, p. 1117.

Karim, S., Papamichail, K.N. and Holland, C.P. (2015), "The effect of prior knowledge and decisionmaking style on the online purchase decision-making process: a typology of consumer shopping behaviour", Decision Support Systems, Vol. 77, pp. 137-147.

Katz, M. and Shapiro, C. (1992), "Product introduction with network effects", Journal of Economic Perspectives, Vol. 8 No. 2, pp. 93-115.

Katz, M.L. and Shapiro, C. (1985), "Network externalities, competition, and compatibility", American Economics Review, Vol. 75, pp. 424-440.

Kazancoglu, I. and Aydin, H. (2018), "An investigation of consumers' purchase intentions towards omni-channel shopping: a qualitative exploratory study", International Journal of Retail and Distribution Management, Vol. 46 No. 10, pp. 959-976.

Kembro, J.H., Norrman, A. and Eriksson, E. (2018), "Adapting warehouse operations and design to omni-channel logistics", International Journal of Physical Distribution and Logistics Management, Vol. 48 No. 9, pp. 890-912.

Kim, E., Park, M.C. and Lee, J. (2017), "Determinants of the intention to use buy-online, pickup in-store (BOPS): the moderating effects of situational factors and product type", Telematics and Informatics, Vol. 34 No. 8, pp. 1721-1735.

Kraemer, K.L., Dedrick, J. and Yamashiro, S. (2000), "Refining and extending the business model with information technology: dell computer corporation", The Information Society, Vol. 16 No. 1, pp. 5-21.

Kulins, C., Leonardy, H. and Weber, C. (2016), "A configurational approach in business model design", Journal of Business Research, Vol. 69 No. 4, pp. 1437-1441.

Kumar, A., Mehra, A. and Kumar, S. (2019), "Why do stores drive online sales? Evidence of underlying mechanisms from a multichannel retailer", Information Systems Research, Vol. 30 No. 1, pp. 319-338. 
Larke, R., Kilgour, M. and O'Connor, H. (2018), "Build touchpoints and they will come: transitioning to omnichannel retailing", International Journal of Physical Distribution and Logistics Management, Vol. 48 No. 4, pp. 465-483.

Lee, Z.W., Chan, T.K., Chong, A.Y.L. and Thadani, D.R. (2019), "Customer engagement through omnichannel retailing: the effects of channel integration quality", Industrial Marketing Management, Vol. 77, pp. 90-101.

Li, Y., Liu, H., Lim, E.T., Goh, J.M., Yang, F. and Lee, M.K. (2018), “Customer's reaction to cross-channel integration in omnichannel retailing: the mediating roles of retailer uncertainty, identity attractiveness, and switching costs", Decision Support Systems, Vol. 109, pp. 50-60.

Li, Y., Li, G., Tayi, G.K. and Cheng, T.C.E. (2019), "Omni-channel retailing: do offline retailers benefit from online reviews?", International Journal of Production Economics, Vol. 218, pp. 43-61.

Lim, S.F.W.T. and Srai, J.S. (2018), "Examining the anatomy of last-mile distribution in e-commerce omnichannel retailing", International Journal of Operations \& Production Management, Vol. 38 No. 9, pp. 1735-1764 doi: 10.1108/ijopm-12-2016-0733.

McGahan, A.M. and Porter, M.E. (2002), "What do we know about variance in accounting profitability?", Management Science, Vol. 48 No. 7, pp. 821-953.

Mesoudi, A. (2011), Cultural Evolution, University of Chicago Press, Chicago.

Milgrom, P. and Roberts, J. (1995), "Complementarities and fit: strategy, structure and organizational change in manufacturing”, Journal of Accounting and Economics, Vol. 19 Nos 2/3, pp. 179-208.

Murugan, N. and Jacob, J. (2019), "A brand view on the user acceptance of mobile apps: an evidence from India in the multi-channel context", International Journal of Electronic Marketing and Retailing, Vol. 10 No. 2, pp. 95-117.

Museba, T.J., Ranganai, E. and Gianfrate, G. (2021), "Customer perception of adoption and use of digital financial services and mobile money services in Uganda", Journal of Enterprising Communities: People and Places in the Global Economy, Vol. 15 No. 2, pp. 177-203.

Nelson, R., Dosi, G., Helfat, C., Pyka, A., Saviotti, P., Lee, K., Dopfer, K., Malerba, F. and Winter, S. (2018), Modern Evolutionary Economics: An Overview, Cambridge University Press, Cambridge.

Norris, D.G. (1993), "Intel inside' branding a component in a business market", Journal of Business and Industrial Marketing, Vol. 8 No. 1, pp. 14-24, doi: 10.1108/08858629310027560.

Parayre, R. (1995), "The strategic implications of sunk costs: a behavioral perspective”, Journal of Economic Behavior and Organization, Vol. 28 No. 3, pp. 417-442.

Phan, D.D. and Vogel, D.R. (2010), "A model of customer relationship management and business intelligence for catalogue and online retailers", Information and Management, Vol. 47 No. 2, pp. 69-77.

Piotrowicz, W. and Cuthbertson, R. (2014), "Introduction to the special issue information technology in retail: toward omnichannel retailing", International Journal of Electronic Commerce, Vol. 18 No. 4, pp. 5-16.

Polacco, A. and Backes, K. (2018), "The amazon go concept: implications, applications, and sustainability", Journal of Business and Management, Vol. 24 No. 1, pp. 79-92, doi: 10.6347/ JBM.201803_24(1).0004.

Porter, M.E. (1985), Competitive Advantage: Creating and Sustaining Superior Performance, Free Press, New York, NY.

Raymond, M.A. and Tanner, J.F. Jr (1994), "Selling and sales management in action: maintaining customer relationships in direct sales: stimulating repeat purchase behavior", Journal of Personal Selling and Sales Management, Vol. 14 No. 4, pp. 67-76.

Rigby, D.K. (2011), “The future of shopping”, Harvard Business Review, Vol. 89 No. 12, pp. 65-76.

Rodrígueztorrico, P., Cabezudo, R.S.J. and Sanmartín, S. (2017), "Tell me what they are like and I will tell you where they buy. An analysis of omnichannel consumer behavior", Computers in Human Behavior, Vol. 68, pp. 465-471.

\section{Value creation through omnichannel practices}

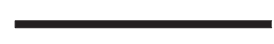


Rogers, E.M. (1995), Diffusion of Innovations, 4th ed., The Free Press, New York, NY.

Rumelt, R. (1991), "How much does industry matter?", Strategic Management Journal, Vol. 12 No. 3, pp. 167-185.

Saghiri, S., Wilding, R., Mena, C. and Bourlakis, M. (2017), "Toward a three-dimensional framework for omni-channel", Journal of Business Research, Vol. 77, pp. 53-67.

Schumpeter, J.A. (1934), The Theory of Economics Development: An Inquiry into Profits, Capital, Credit, Interest, and the Business Cycle, Harvard University Press, Cambridge, MA.

Schumpeter, J.A. (1942), Capitalism, Socialism and Democracy, Harper, New York, NY.

Shen, X.-L., Li, Y.-J., Sun, Y. and Wang, N. (2018), "Channel integration quality, perceived fluency and omnichannel service usage: the moderating roles of internal and external usage experience", Decision Support Systems, Vol. 109, pp. 61-73.

Sheremata, W.A. (2004), "Competing through innovation in network markets: strategies for challengers", Academy of Management Review, Vol. 29 No. 3, pp. 359-377.

Shi, S., Wang, Y., Chen, X. and Zhang, Q. (2020), "Conceptualization of omnichannel customer experience and its impact on shopping intention: a mixed-method approach", International Journal of Information Management, Vol. 50, pp. 325-336.

Silva, S.C., Duarte, P. and Sundetova, A. (2020), "Multichannel versus omnichannel: a price-segmented comparison from the fashion industry", International Journal of Retail and Distribution Management, Vol. 48 No. 4, pp. 417-430.

Srinivasa, S., Rutz, O.J. and Pauwels, K. (2016), "Paths to and off purchase: quantifying the impact of traditional marketing and online consumer activity", Journal of the Academy of Marketing Science, Vol. 44 No. 4, pp. 440-453.

Standing, C. and Vasudavan, T. (2000), "The impact of internet on travel industry in Australia", Tourism Recreation Research, Vol. 25 No. 3, pp. 45-54.

Suarez, F. (2005), "Network effects revisited: the role of strong ties in technology selection", Academy of Management Journal, Vol. 48 No. 4, pp. 710-722.

Swan, E.L., Dahl, A.J. and Peltier, J.W. (2019), "Health-care marketing in an omni-channel environment", Journal of Research in Interactive Marketing, Vol. 13 No. 4, pp. 602-618.

Teece, D.J. (2010), "Business models, business strategy and innovation”, Long Range Planning, Vol. 43 Nos 2/3, pp. 172-194.

Verhoef, P.C., Kannan, P.K. and Inman, J.J. (2015), "From multi-channel retailing to omni-channel retailing: introduction to the special issue on multi-channel retailing", Journal of Retailing, Vol. 91 No. 2, pp. 174-181.

Wadman, R. and Hütt, R. (2004), "The need for a new go-to-market strategy in Europe: how to survive and thrive in the new more complex healthcare marketplace", Journal of Medical Marketing, Vol. 4 No. 2, pp. 154-162, doi: 10.1057/palgrave.jmm.5040156.

Writz, B.W., Pistoia, A., Ullrich, S. and Göttel, V. (2016), "Business models: origin, development and future research perspectives", Long Range Planning, Vol. 49 No. 1, pp. 36-54.

$\mathrm{Xu}, \mathrm{X}$. and Jackson, J.E. (2019), "Examining customer channel selection intention in the omni-channel retail environment”, International Journal of Production Economics, Vol. 208, pp. 434-445.

Yim, D.S. and Han, S.S. (2016), "Omni channel's perception effect on omnichannel use and customerbrand relationship", The Journal of Distribution Science, Vol. 14 No. 7, pp. 83-90.

Zhang, J., Xu, Q. and He, Y. (2018a), "Omnichannel retail operations with consumer returns and order cancellation", Transportation Research Part E: Logistics and Transportation Review, Vol. 118, pp. 308-324.

Zhang, M., Ren, C., Wang, G.A. and He, Z. (2018b), "The impact of channel integration on consumer responses in omni-channel retailing: the mediating effect of consumer empowerment", Electronic Commerce Research and Applications, Vol. 28, pp. 181-193. 
Zott, C. and Amit, R. (2007), "Business model design and the performance of entrepreneurial firms", Organization Science, Vol. 18 No. 2, pp. 181-199.

Zott, C. and Amit, R. (2008), "The fit between product market strategy and business model: implications for firm performance”, Strategic Management Journal, Vol. 29 No. 1, pp. 1-26.

\section{Further reading}

Davis, G.B. and Olson, M.H. (1974), MIS, conceptual foundations, structure and development. Internation Student Edition, New Delhi, 319.

Zaki, M. (2019), "Digital transformation: harnessing digital technologies for the next generation of services", Journal of Services Marketing, Vol. 33 No. 4, pp. 429-435.

\section{Appendix. Summary of studies of omnichannel practices: theoretical lenses and contri- butions to understanding omnichannel practices}

The theory of planned behavior (TPB) seems to have influenced researchers in this area. The TPB posits that an individual's (e.g. a customer's) intention to perform a given behavior (e.g. behavioral intention for making a purchase) depends upon that individual's attitude toward performing that behavior. As per the expectancy-value model, this attitude is shaped by the belief that this purchase will be favorable for the purchaser. The process of attitude formation is critical. This is where channel capabilities that help customers evaluate products become important (Ajzen, 1991; Kumar et al., 2019). Based on the TPB, Murugan and Jacob (2019) presented a research model of pure online retailers that trade products through e-commerce sites and mobile apps. The authors explored the implications of four factors: the online retail brand, perceived tie, perceived ease of use and perceived similarity in the acceptance of mobile apps. These four factors were found to be important in determining the successful acceptance of mobile apps. Mobile apps are better than mobile browsers because data storage on mobile phones enables faster processing of user requests. This faster processing helps retailers stay connected with customers. Kumar et al. (2019) used the TPB together with prospect theory to identify two underlying mechanisms: store engagement effect and the store return effect. These two mechanisms could explain the complementary effect of stores on online sales. The authors showed that these two effects increase with more store openings near customers' locations. Xu and Jackson (2019) examined the influence of channel transparency, convenience and uniformity on customers' perceived behavioral control. They found that all three attributes positively influence perceived behavioral control. This research may enable omnichannel retailers to understand customer perceptions and needs and to improve their offerings and supply chain management to attract more customers.

Diffusion of innovation (DOI) theory demonstrates that "an innovation is communicated through certain channels over time among the members of a social system" (Rogers, 1995, p. 1). Innovation refers to "an idea, practice, or object that is perceived as new by an individual or another unit of adoption" (Rogers, 1995, p. 1). DOI theory explains potential users' (or consumers') decisions to reject or adopt an innovation based on these users' beliefs or attitudes toward the innovation. The five attributes of innovations that shape the attitudes and beliefs toward innovation are relative advantage, compatibility, complexity, trialability and observability (Kim et al., 2017; Rogers, 1995). Drawing on DOI theory, Shi et al. (2020) investigated the underlying mechanisms of certain omnichannel attributes in customers' usage. The authors also considered customers' shopping habits in the innovative shopping environment and investigated how omnichannel experience influences customers' perceived compatibility. By adopting DOI, the study approached the formation of customers' omnichannel shopping as a tradeoff between compatibility and risk. The results of the
Value creation through omnichannel practices 
study highlight the key determinants of omnichannel experience that altogether affect customers' behavioral beliefs and intentions in omnichannel shopping. Kim et al. (2017) used the attributes of DOI theory to demonstrate consumers' attitudinal and belief structures about buy-online, pickup instore (BOPS). The aforementioned study showed that consumers who perceive online shopping as risky have higher intention to use BOPS. This finding provides evidence of how BOPS can complement online-only businesses by reducing the risk of online shopping.

The technology acceptance model (TAM) has also been applied in omnichannel research. The TAM has shown the mediating role of user evaluations of a new technology and the key role of system attributes as antecedents of these evaluations. Behavioral intentions are influenced by attitudes, which are general impressions of a technology. The TAM suggests that when users are presented with a new technology, a number of factors influence their decisions about how and when they will use it. First, perceived usefulness means whether or not someone perceives that technology to be useful for what they want to do. Second, perceived ease-of-use means that if the technology is easy to use, then the barriers are conquered. If it is not easy to use and the interface is complicated, then no one will have positive attitudes toward it. Applying the TAM, Yim and Han (2016) found that omnichannel's perceived ease of use has a significant positive effect on perceived usefulness. Moreover, omnichannel's perceived ease of use and perceived usefulness has a significant positive effect on omnichannel use. The use of omnichannel has a significant positive effect on the brandcustomer relationship. The aforementioned study showed the intermediate relationship between perceived ease of use and omnichannel use. In the context of health care and telemedicine, Swan et al. (2019) applied the TAM, finding that attitudinal constructs related to telemedicine's benefits, including access and health decision-making, have the strongest impact on future telemedicine usage. The study also empirically showed a link between consumers' omnichannel information seeking and telemedicine usage. Although omnichannel improves shared decision-making, marketers must adopt strategies according to consumers' evolving omnichannel preferences for access and information exchange to combine digital service offerings with interpersonal touchpoints. Juaneda-Ayensa $e t$ al. (2016) observed that the key determinants of purchase intention in an omnichannel context are, in order of importance, personal innovativeness, effort expectancy and performance expectancy. Factors such as habit, hedonic motivation, social influence and perceived security have no influence on omnichannel shopping.

He et al. (2020) applied game theory to obtain the retailer's optimal ordering and pricing decisions under the benchmark scenario and omnichannel strategy. Game theory is the process of modeling strategic interactions between two or more players in a situation containing set rules and outcomes. For any situation with two or more players that involves known payouts or quantifiable consequences, game theory can be used to help determine the most likely outcomes. Li et al. (2019) applied game theory to study the effect of online reviews in omnichannel retailing, finding that offline retailers are willing to adopt third party reviews (TPRs) as long as their products are recommended by the TPRs (under the TPR-only strategy). It is also beneficial to integrate online consumer reviews (OCRs) and TPRs simultaneously (under the OCR-TPR strategy). In addition, they compared all feasible strategies and found that the OCR-TPR strategy is optimal most of the time.

Complex adaptive systems (CAS) theory has also been applied to omnichannel/multichannel research. CASs have the following core elements and features: agents, connectivity, emergence and autonomy/control. While a complicated system (e.g. a jet engine) can be viewed as the sum of its parts, a complex system cannot be viewed that way. One cannot predict the behavior of a complex system by examining the behavior of its individual parts (Choi et al., 2001; Saghiri et al., 2017). Saghiri et al. (2017) applied CAS theory to conceptualize omnichannel systems in a three-dimensional framework: customer value-adding journey (i.e. where the channels are located), type of channel 
(i.e. the way the product or information is transferred and may vary in each stage of the customer value-adding journey) and agents (i.e. the person or persons responsible for each channel, which may differ for each stage of the customer value-adding journey and each channel type). The authors found that channel visibility and integration among channel stages, channel types and channel agents are the main enablers of operationalizing an omnichannel system.

Lee et al. (2019) applied social exchange theory (SET) to study omnichannel. SET is built on the principles of equity and reciprocity. SET posits that exchange parties seek to derive mutual benefits. In particular, when parties perceive that they have obtained benefits from another, they will feel indebted and will be obliged to reciprocate in kind. Using SET, the authors proposed that channel integration quality initiatives by omnichannel retailers will be reciprocated with customers engaged with the retailers. This reciprocity in turn leads to desirable business outcomes. The authors built a research model on this understanding and tested four hypotheses. H1: Channel-service configuration is positively related to customer engagement. $H 2$ : Integrated interactions are positively related to customer engagement. H3: Customer engagement is positively related to repurchase intention. H4: Customer engagement is positively related to positive word-of-mouth. All four hypotheses were supported by the data analysis.

Shen et al. (2018) applied the Wixom and Todd model to study channel integration quality, perceived fluency and omnichannel service usage. The Wixom and Todd model explains how people interact with a focal technology and how their perceptions toward using the technology affect their subsequent usage behavior. Shen et al. (2018) extended the Wixom and Todd model by including usage experience as an individual behavior-based trait. They further examined its moderating effect on the link between behavioral beliefs and usage behavior. This study suggests that omnichannel service providers should offer more channels for customers to access a specific service and help customers understand how to use and integrate different channels to achieve their needs. For example, service providers can design some game tasks to familiarize customers with switching between channels.

Emrich et al. (2015) applied negativity bias theory. The negativity bias, also known as the negativity effect, is the notion that, even when of equal intensity, things of a more negative nature (e.g. unpleasant thoughts, emotions or social interactions or harmful or traumatic events) have a greater effect on one's psychological state and processes than neutral or positive things. In other words, something very positive will generally have less of an impact on a person's behavior and cognition than something equally emotional but negative. Emrich et al. (2015) conducted two large-scale experimental studies to empirically investigate whether a dominant multichannel integration strategy exists in the context of full and simultaneous information and more uncertain and subsequent information accessibility. Drawing on negativity bias theory, the authors consistently found that full integration dominates no integration across assortment relations, but asymmetric integration - the most common strategy among multichannel retailers - can have a detrimental effect for substitutive relations compared with no integration. Asymmetric integration can be more beneficial than full integration for independent relations, while customer outcomes differ less for complementary relations.

Li et al. (2018) applied the push-pull-mooring (PPM) framework to study customer reactions to cross-channel integration in omnichannel retailing. The PPM framework indicates that customers' switching behavior may be affected by push factors. Pull effects reflect customers' willingness to maintain a relationship owing to genuine appreciation of the quality attributes of service providers. Mooring effects denote a customer's cost-benefit analysis of a retailer relative to viable alternatives. These effects may oblige customers to continue an existing relationship with a retailer due to economic, social or psychological costs. The authors applied the PPM framework to present a research model describing how customers react to retailers' cross-channel integration.

\section{Value creation through omnichannel practices}

117 
Zhang et al. (2018a, 2018b) examined the impact of channel integration on consumer responses in omnichannel retailing by applying the stimulus-organism-response (SOR) framework. The SOR framework describes the relationship between the stimulus (S), consumers' internal states $(\mathrm{O})$ and subsequent behavior (R). The stimulus influences consumers' internal states, which is followed by their changed behavior. With the SOR framework, the stimulus may be marketing-related factors or environmental characteristics, such as store atmosphere and website features. The organism in the SOR framework represents the internal states of consumers. The organism includes not only internal activities such as perception, feeling and thinking but also affective, emotional and cognitive states such as pleasure and satisfaction. Compared with the perceptions and evaluations of consumers, their shopping behaviors, such as their intentions to use, browse and buy, are generally thought of as responses in the SOR framework. Zhang et al. (2018a, 2018b) considered channel integration, a new and special characteristic in the omnichannel retailing environment, as the stimulus. They considered consumer empowerment as the organism in their research because it focused on consumer perceptions of control over the shopping process. Satisfaction and trust were also regarded as the organism in their model. They used consumer purchase intention as the response in the model.

\section{Corresponding author}

Ricardo Costa Climent can be contacted at: ricardo.costacliment@im.uu.se

For instructions on how to order reprints of this article, please visit our website: www.emeraldgrouppublishing.com/licensing/reprints.htm Or contact us for further details: permissions@emeraldinsight.com 